\title{
Influence of Bolus Temperature on Human
}

\section{Esophageal Motor Function}

\author{
D. H. Winship, S. R. Viegas de Andrade, and F. F. Zboralske \\ From the Departments of Medicine and Radiology, Marquette School of \\ Medicine, and Milwaukee County General Hospital, \\ Milwaukee, Wisconsin 53226
}

\begin{abstract}
A B S T RACT Hot and cold water, in comparison to room temperature water, ingested by normal young men, profoundly alters esophageal motor function. Cold water slows or abolishes esophageal peristalsis, prolongs the contraction wave in the distal esophagus, produces a delayed but prolonged relaxation of the lower esophageal sphincter, and regularly causes a lower esophageal sphincteric contraction of increased amplitude. It does not, however, diminish the frequency of response of the lower esophageal sphincter even when the peristaltic wave above is abolished. Hot water, on the other hand, accelerates the response of the esophagus to the swallow; this change is reflected by increased speed of wave propagation, waves of shorter duration, a more brief relaxation of the lower esophageal sphincter, and a lower esophageal sphincter contraction of less amplitude. Hot water may even increase the frequency of peristalsis at least in the proximal esophagus. In spite of these changes, however, neither extreme of temperature altered the rapid passage of the water swallows through the more proximal portions of the esophagus. Hot water tended to traverse the lower esophageal sphincter more rapidly than did room temperature water, but cold water was often delayed in entering the stomach and tended to pool in the distal esophagus even though sphincteric relaxation was manometrically complete and prolonged.
\end{abstract}

An abstract of this work (in part) appeared in 1968 Gastroenterology. 54: 1306.

Dr. Winship's present address is the Department of Medicine, University of Missouri School of Medicine, Columbia, Mo., Dr. Viegas de Andrade's is $1^{\mathbf{\Lambda}}$ Cadeira de Clínica Médica, Faculdade Nacional de Medicine Da Universidade Federal Do Rio de Janeiro, Brazil, and Dr. Zboralske's is the Department of Radiology, Stanford University Medical Center, Palo Alto, Calif.

Received for publication 24 June 1969 and in revised form 31 July 1969.

\section{INTRODUCTION}

The everyday task of the human esophagus is to convey food and drink from mouth to stomach. This task is accomplished by a complex and highly coordinated pattern of esophageal muscular activity. The body of literature which describes the motor function of the human esophagus, however, is virtually bereft of information concerning the influence of the bolus per se upon esophageal motor function.

We have investigated the effects of hot and cold water swallows upon esophageal motility in normal man and have compared the results to those obtained with room temperature water swallows. The results show that the temperature of ingested liquids profoundly alters esophageal motor function.

\section{METHODS}

\section{Subjects}

11 healthy young men volunteers were studied. None had evidence of gastrointestinal disease.

\section{Technique}

Intraluminal esophageal pressures were determined by means of two open-tipped, water-filled, pump-perfused $(0.8 \mathrm{ml} /$ min), polyvinyl catheters of $1.8 \mathrm{~mm}$ I.D. fused longitudinally with the recording tips $10 \mathrm{~cm}$ apart. Pressures were transmitted to Sanborn pressure transducers (Sanborn Division, Hewlett-Packard Co., Waltham, Mass.) and registered on a multichannel direct writing Sanborn Recorder, paper speed $2.5 \mathrm{~mm} / \mathrm{sec}$.

A bead thermistor (General Electric Type 81B105, Allied Radio Corp., Chicago, Ill.) was placed adjacent to each tip for temperature recording. Each thermistor functioned as the variable resistance of a Wheatstone bridge. Changes in temperature at the bead thermistor cause variations in the voltage of a current passing through the bridge. These variations were also registered on two separate channels of the Sanborn recorder simultaneous with the intraluminal pressure recordings. The time constant of these thermistors (time for thermistor to indicate $63 \%$ of new impressed temperature) is given by the manufacturer as $2 \mathrm{sec}$. 
Respirations were determined from a pneumographic belt, placed around the chest of the subjects, and registered on a fifth recording channel; a similar belt around the neck was used to register deglutition movements on the same channel.

All studies were performed with the subject in the sitting position; tubes were passed through the mouth.

Body of the esophagus, distal half. During the initial part of the study we compared the effects of hot, cold, and room temperature water swallows upon the motor function of the distal portion of the body of the esophagus. The lower esophageal sphincter (LES) was located manometrically; the distal temperature-pressure recording tip was positioned $2 \mathrm{~cm}$ above the proximal margin of the LES and the tube assembly was taped in place. Seven series of swallows were taken by the subject. Each series consisted of twelve $15-\mathrm{ml}$ swallows of water at room temperature (RT) $\left(23-26^{\circ} \mathrm{C}\right)$, cold (C) water $\left(0.5-3^{\circ} \mathrm{C}\right)$, or hot $(\mathrm{H})$ water $\left(58-61^{\circ} \mathrm{C}\right)$. The swallows were taken in succession at intervals of $20-30$ sec. The usual sequence was RT, C, RT, RT, H, RT, RT. In a few subjects the position of $\mathrm{C}$ and $\mathrm{H}$ were reversed in the sequence. In some subjects additional sequences were performed on other days consisting of only four series, either RT, C, RT, RT, or RT, H, RT, RT. The results were independent of the sequence followed. The initial sequence listed above was thus utilized for tabulation of the data.

Lower esophageal sphincter. On a second day the LES was manometrically located by its intraluminal pressure characteristics, its distal margin was determined and the proximal recording tip and thermistor were placed $2 \mathrm{~cm}$ below that point. The subject then drank $100 \mathrm{ml}$ of RT water. The catheter was subsequently withdrawn by $0.5 \mathrm{~cm}$ increments and $15 \mathrm{ml}$ of water was swallowed at each station. When the distal recording tip reached the point $2 \mathrm{~cm}$ above the proximal margin of the LES, the series of swallows was interrupted and the proximal recording tip was replaced at the initial position $2 \mathrm{~cm}$ beyond the distal margin of the LES. This sequence was performed four times, first using RT water, then $C$ water, then $R T$ water, and finally $H$ water, in that order. After the initial $100 \mathrm{ml}$ bolus was swallowed, the $15-\mathrm{ml}$ swallows were taken at 20 - to $40-\mathrm{sec}$ intervals.

Upper esophageal sphincter (UES) and body of esophagus, proximal half. On another day, the UES was located
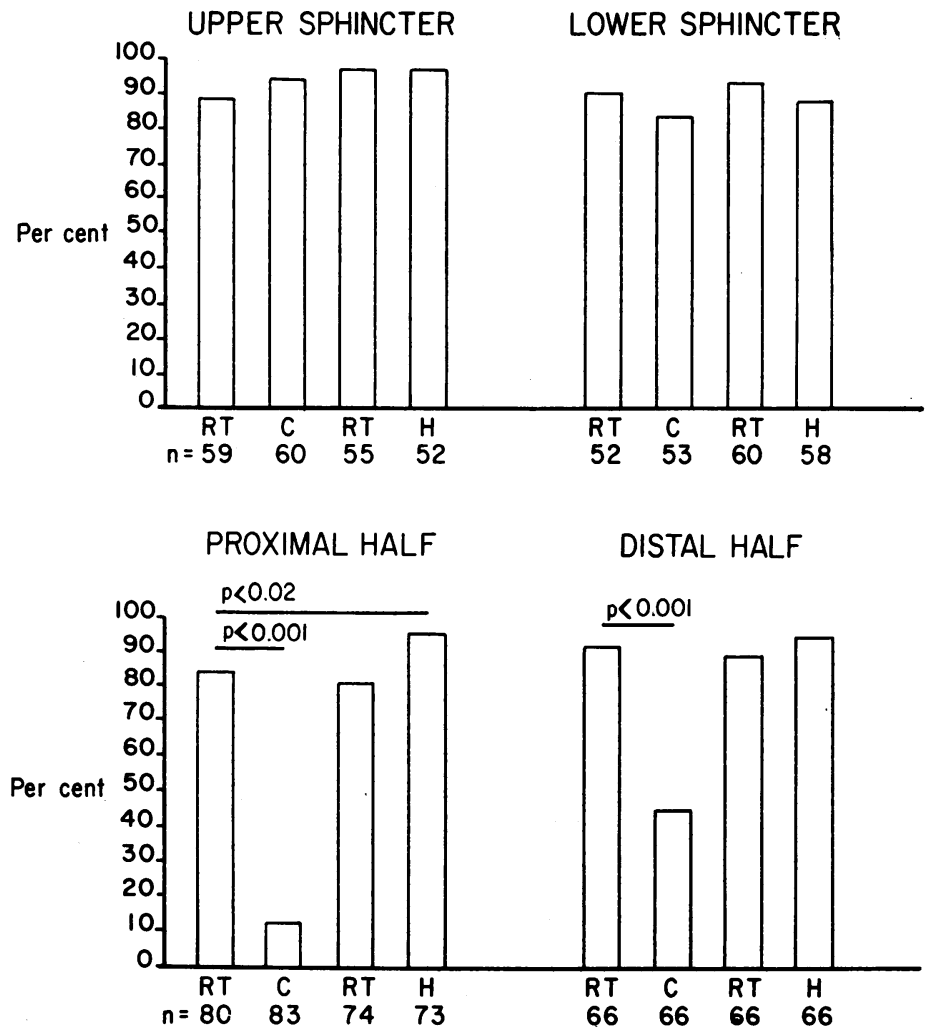

FiguRE 1 Frequency of motor response to water swallows. Graphs designated Upper Sphincter and Lower Sphincter represent frequency of sphincteric relaxation after water swallows. Graphs designated Proximal Half and Distal Half refer to peristalsis in the body of the esophagus. Statistical significance of differences, using initial RT series as control, are shown by horizontal lines and " $P$ " values extending between appropriate bars. (See text to note differences in methods of calculating results in Proximal and Distal halves.) $\mathrm{RT}$, room temperature; $\mathrm{C}$, cold; $\mathrm{H}$, hot; and $\mathrm{n}$, number of swallows upon which observations are based. 
Duration of Relaxation

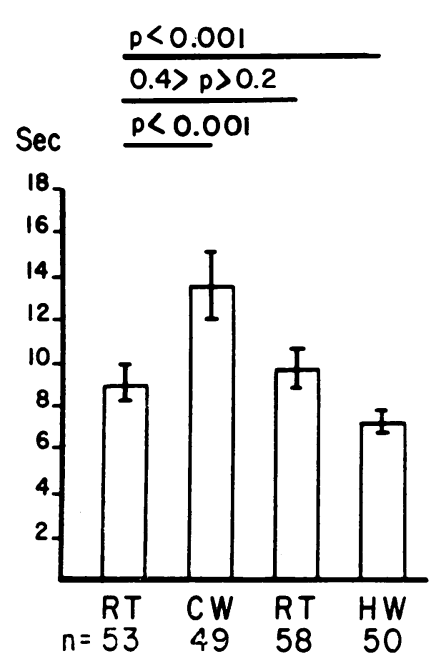

Delay for

Maximal Relaxation
Amplitude of Contraction
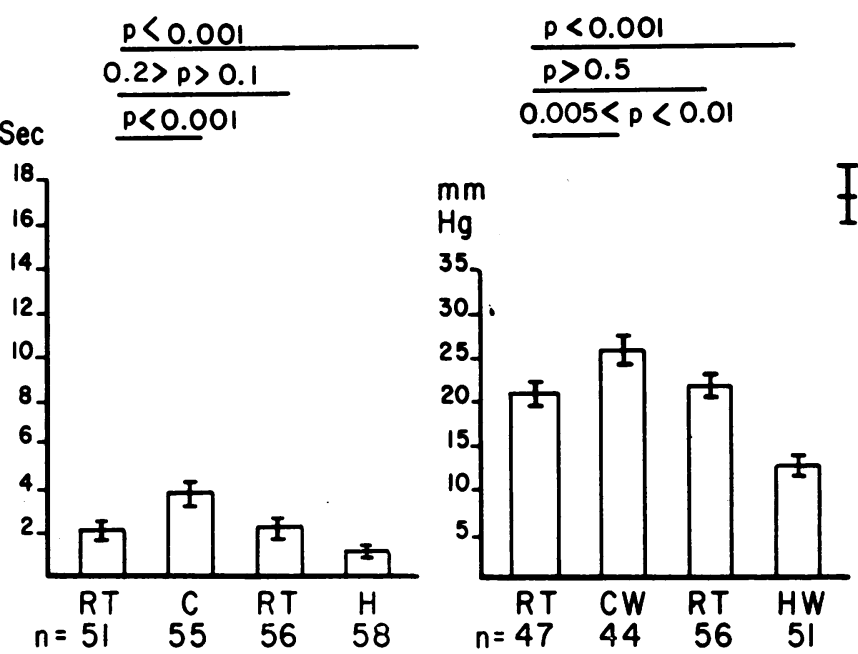

Figure 2 Lower esophageal sphincter.

manometrically and the proximal recording tip was placed $2 \mathrm{~cm}$ below its distal margin. The subject drank the $100 \mathrm{ml}$ "loading dose" and then performed water swallows in a fashion identical to that described for the LES. Intraluminal pressures were recorded exactly as was done for the LES except that now the distal tip registered pressures in the proximal body of the esophagus. In addition, two swallows were taken at each station instead of one as in the LES.

In the study of the distal half of the body of the esophagus, the recording tips were kept stationary; only the last six swallows in each series were used for tabulation since the temperature-induced changes occurred rapidly but stabilized only after the third to fifth swallows of each series. For the study of both the LES and the UES, it was desirable to include the responses obtained at every station as the recording tips were pulled through the sphincters. We therefore introduced the initial loading dose of $100 \mathrm{ml}$ for investigation of the sphincters since preliminary studies showed that the changes were rapidly and satisfactorily established by this maneuver.

Analysis of records. Gastric fundal pressure was regarded as zero or base line for pressures in the LES; resting pressure in the body of the esophagus was taken as base line for pressures recorded in the UES and esophageal body. Appropriate corrections were made for changes in base line pressure caused by the progressive upward displacement of recording catheters during the study of both sphincters in the sitting subjects. Amplitude of peristaltic wave peaks, degree of sphincteric contraction and relaxation are reported in millimeters $\mathrm{Hg}$. Each measurement referred to its appropriate base line. All pressures analyzed are endexpiratory except the peristaltic peak pressure in the body of the esophagus and contraction and relaxation in the UES. Duration of relaxation of sphincters was measured as the time lapse, in seconds, between the initiation of the pressure decrease after swallow and the onset of the postswallow contraction. This same starting point was used to define the time required for the sphincter to achieve maximum relaxation.
Duration of peristaltic wave contraction was measured, in seconds, from onset of the major upstroke of the monophasic wave to the point where the downstroke returned to base line. Peristaltic speed (in centimeters per second) was calculated from wave onsets from those swallowing complexes resulting in monophasic waves. In instances in which the peristaltic wave did not occur, no value for speed was assigned.

Mean and standard error of means of data were calculated by standard techniques; the statistical significance of differences were calculated by Student's $t$ test. Differences in frequency of response were analyzed by chi-square calculations (1).

\section{RESULTS}

Lower esophageal sphincter. The frequency with which the LES relaxed (or contracted) after swallow was not altered by changes in bolus temperature (Fig. 1). The duration of sphincter relaxation and the amplitude of contraction after the relaxation, however, were altered (Fig. 2). C water significantly prolonged the duration of relaxation and increased the amplitude of contraction (Fig. 2); $\mathrm{H}$ water shortened the duration of relaxation and decreased the amplitude of contraction.

The degree of the maximal relaxation of the LES was not changed by the different boluses. However, C water significantly prolonged the time interval between onset of relaxation and the moment the sphincter achieved its maximal relaxation. $\mathrm{H}$ water shortened this interval $(P<0.001)$ for both differences) (Fig. 2).

Recordings from both thermistors, while the proximal one was above the LES and the distal one within or below the LES, frequently showed a delay in the initial deflection recorded from the distal thermistor, 
indicating that $\mathrm{C}$ water often pooled in the distal esophagus and traversed the LES after a much longer time interval than did RT or $\mathrm{H}$ water (Fig. 3 ). On the other hand, although brisk changes in both thermistor records almost invariably occurred with $\mathrm{RT}$ and $\mathrm{H}$ water, on many occasions the changes in the distal thermistor were so poorly defined with $\mathrm{C}$ water that the time required for the bolus to travel between thermistors could not be estimated. For this reason, statistical significance of these differences was not sought. The longest delay registered, however, was $18.4 \mathrm{sec}$ for a swallow of $\mathrm{C}$ water (mean delay $3.0 \mathrm{sec}$ ), $5.8 \mathrm{sec}$ for a RT water swallow (mean delay $1.9 \mathrm{sec}$ ), and $4.2 \mathrm{sec}$ with an $\mathrm{H}$ water swallow (mean delay $1.8 \mathrm{sec}$ ).

Body of the esophagus. Cold water swallows markedly decreased the frequency of peristalsis in both proximal $(P<0.001)$ and distal $(P<0.001)$ halves of the esophagus. These temperature-induced changes sub-
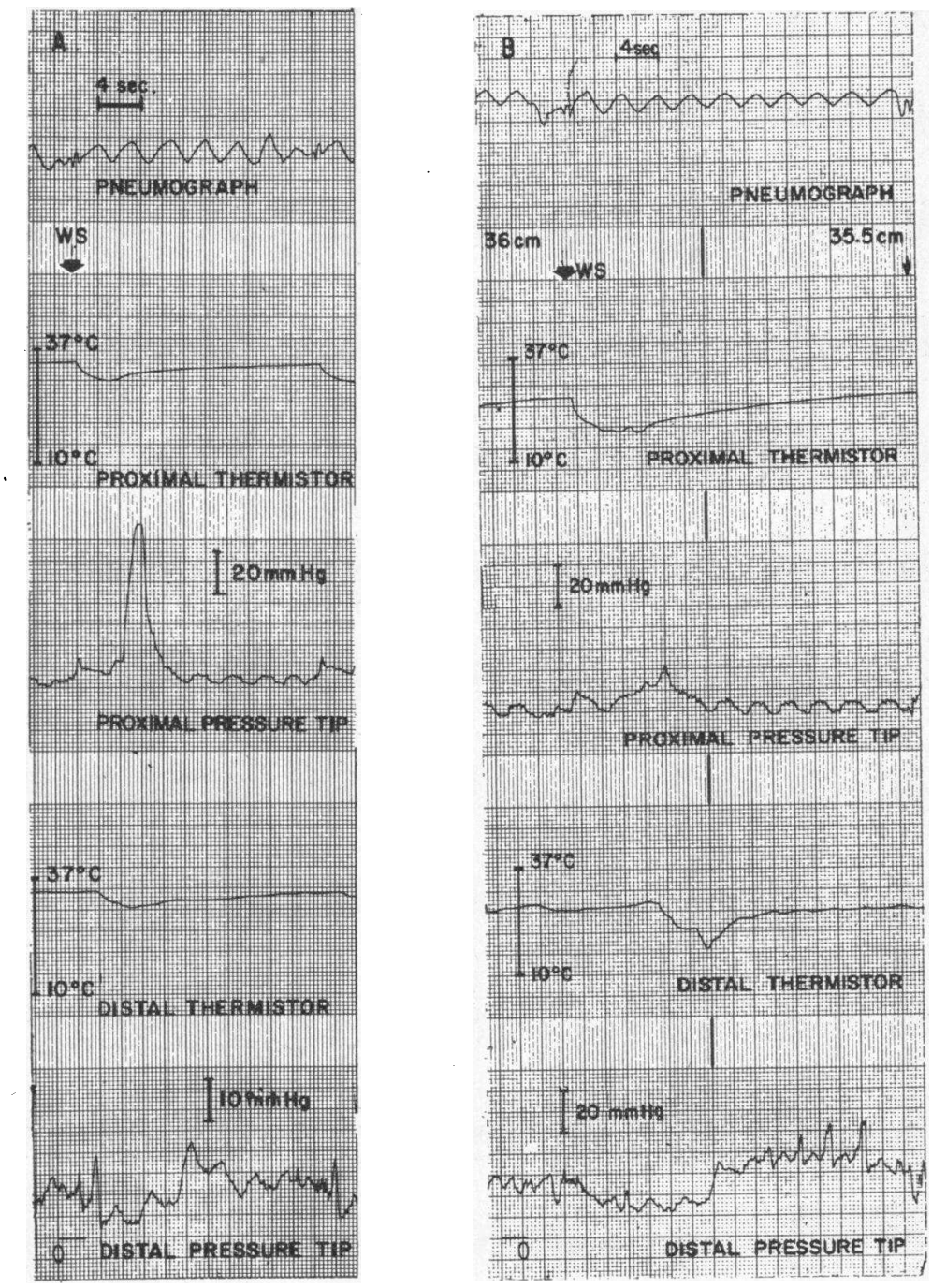

FIGURE 3 Pressure and thermistor record of lower esophageal sphincter and distal half of the body of the esophagus during RT (A) and C water swallows (B). Both examples are from the same subject, taken from midsequence. Distal tip and thermistor are within the LES. The ingestion of $C$ water has resulted in prolonged relaxation of the lower esophageal sphincter and marked diminution of the amplitude of the wave in the body of the esophagus whereas the contraction of the sphincter is more forceful (note the difference in standardization of the distal pressure tips). The transit time between thermistors was $2 \mathrm{sec}$ for RT water and $6 \mathrm{sec}$ for $\mathrm{C}$ water. WS = wet swallow. 
sided rapidly during the series of $\mathrm{RT}$ swallows immediately after the $\mathrm{C}$ or $\mathrm{H}$ water swallows. We therefore show graphically only the results from the $\mathrm{C}$ and $\mathrm{H}$ water series, and for comparison, those series of RT swallows which immediately preceded them (Fig. 1).

The abolition of the monophasic waves, when it occurred, was invariably noted in both recording sites in the distal esophagus. In the study of the proximal half of the esophagus, each series of swallows began with three or four swallows with the proximal recording tip in the body of the esophagus $2 \mathrm{~cm} \mathrm{distal} \mathrm{to} \mathrm{the} \mathrm{up-}$ per sphincter which presumably was within the striated muscle portion of the esophagus. Abolition of the monophasic wave was not observed at this site but did occur with great frequency at the distal recording tip (Fig. 4).

Hot water swallows increased the peristaltic frequency slightly in the proximal half of the esophagus $(P<0.02)$. A similar difference was even smaller in the distal half and was statistically not significant $(P>$ 0.3) (Fig. 1).

The speed of peristalsis was markedly influenced by the temperature of the bolus (Fig. 5). Those waves

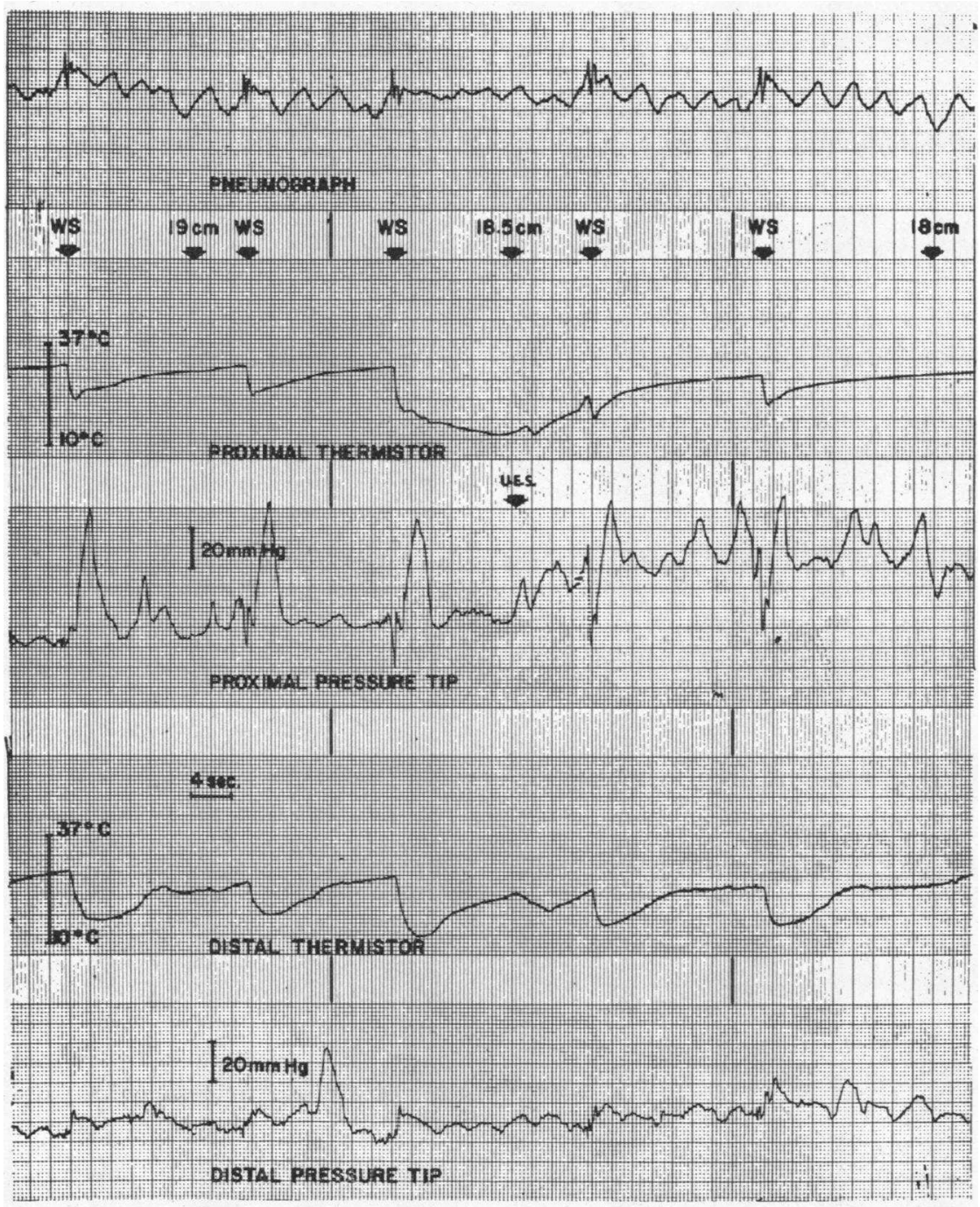

FIgURE 4 Pressure and thermistor record of upper esophageal sphincter (Proximal tip and thermistor) and proximal body of the esophagus. Distal tip and thermistor are $10 \mathrm{~cm}$ distal to proximal tip and thermistor. This section of the tracing is taken from midsequence of cold water swallows. The ingestion of $\mathrm{C}$ water has caused abolition of peristalsis at the distal tip, but no alteration in function occurs in the upper sphincter or esophagus immediately below it. $\mathrm{Cm}$ refers to distance of proximal tip and thermistor from incisor teeth; WS = wet swallow $\left(15 \mathrm{ml}\right.$ of water at $\left.1^{\circ} \mathrm{C}\right)$. 
which occurred during the $\mathrm{C}$ water sequences were propagated at a much slower rate than the waves initiated by RT swallows in both proximal $(P<0.001)$ and distal $(P<0.001)$ halves of the esophagus. Hot water swallows, on the other hand, caused acceleration of wave propagation (proximal half $P<0.005$; distal half $P<0.001$ ).

The rapidity with which changes were effected, then subsided, is illustrated in Fig. 6.

The duration of the monophasic wave was prolonged in the distal half of the esophagus by the $C$ water swallows $(P<0.001)$ but not in the proximal half $(P>0.5)$, whereas $\mathrm{H}$ water caused a shortening of the contraction in both regions $(P<0.001$ for both proximal and distal halves) (Fig. 7).

Amplitude of the monophasic waves varied widely and without relation to bolus temperature.

The changes in the pressure waves of the body of the esophagus due to ingestion of either $\mathrm{C}$ or $\mathrm{H}$ water did not alter the speed with which the head of the bolus traversed the esophageal segment delineated by the recording thermistors. The rate of bolus passage down the esophagus, calculated from the initial deflections of the thermistor records, varied between 24.5 and $35.2 \mathrm{~cm} / \mathrm{sec}$ regardless of the segment of esophagus examined.

Upper esophageal sphincter. Wide variations in depth of relaxation and amplitude of contraction occurred, and consistent changes attributable to alterations in bolus temperature were not recognized.

Variations in maximal temperature deviation from base line during the series of swallows occurred, but similar ranges were seen for a given bolus temperature regardless of the site of recording within the esophagus. For example, the lowest temperature reached during individual $\mathrm{C}$ swallows ranged between $11-25^{\circ} \mathrm{C}$ in the $\mathrm{LES}, 10-23^{\circ} \mathrm{C}$ in the body of the esophagus, and $13-25^{\circ} \mathrm{C}$ in the UES. For $\mathrm{H}$ water swallows, these values were

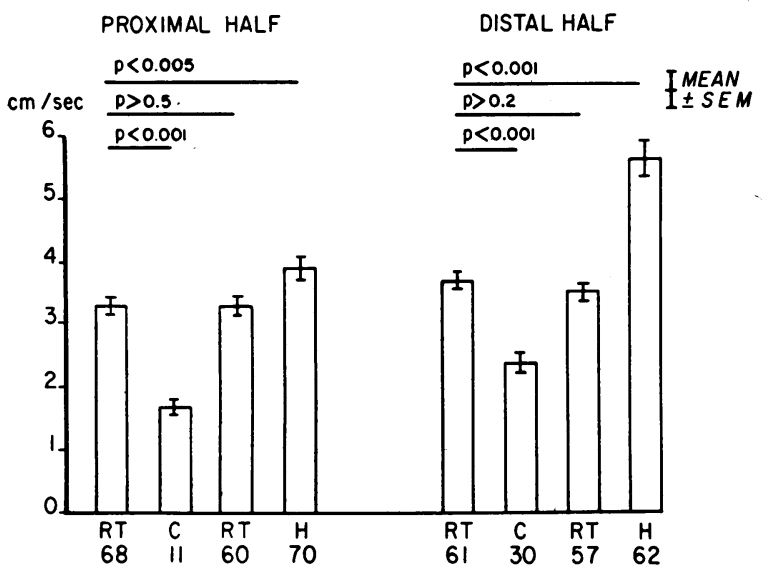

FIGURE 5 Speed of peristalsis in the body of the esophagus.
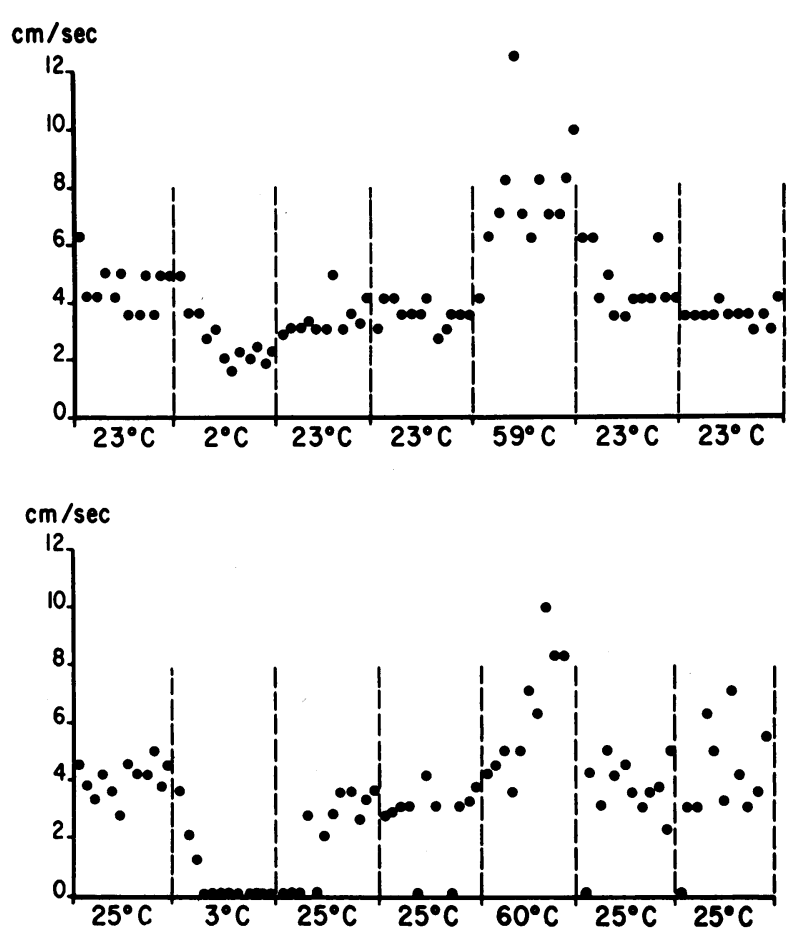

FIGURE 6 Sequential changes in speed of peristalsis developed during complete studies of the distal half of the body of the esophagus in two subjects. Each dot represents the speed of a single peristaltic wave in the sequence observed (abolition of waves is shown here as $0 \mathrm{~cm} / \mathrm{sec}$ only for illustrative purposes; tabulation of peristaltic speed otherwise included only waves which were present). The swallows were taken at 20 - to 30 -sec intervals. Upper-progressive slowing of the peristaltic wave occurred with the first few swallows of $C$ water, but the waves were not abolished. Speed rapidly returned essentially to control values on resuming RT swallows. Hot water swallows rapidly produced increase in peristaltic speed; this change abated rapidly. Lower-progressive slowing of the waves with $\mathrm{C}$ water swallows resulted in abolition of the waves. Recovery was prompt from both $\mathrm{C}$ and $\mathrm{H}$ swallows. Temperature of ingested water (in degrees Centigrade) is shown along the horizontal line.

$55-44^{\circ} \mathrm{C}$ in the LES, $54-43^{\circ} \mathrm{C}$ in the body of the esophagus, and $52-45^{\circ} \mathrm{C}$ in the UES. Peristalsis was abolished only in instances in which the temperature fell to $23^{\circ} \mathrm{C}$ or below. The mean temperature at the point of maximal deviation from base line was virtually identical, however, for those swallows resulting in no peristaltic wave $\left(16.6^{\circ} \mathrm{C}\right.$; range $\left.10-23^{\circ} \mathrm{C}\right)$ and for those followed by a peristaltic wave $\left(16.8^{\circ} \mathrm{C}\right.$; range $\left.13-22^{\circ} \mathrm{C}\right)$.

\section{DISCUSSION}

Casual observations of human eating and drinking habits suffice to show that iced and hot beverages are frequently ingested by many people, at least in our society. The temperature of iced drinks should vary 


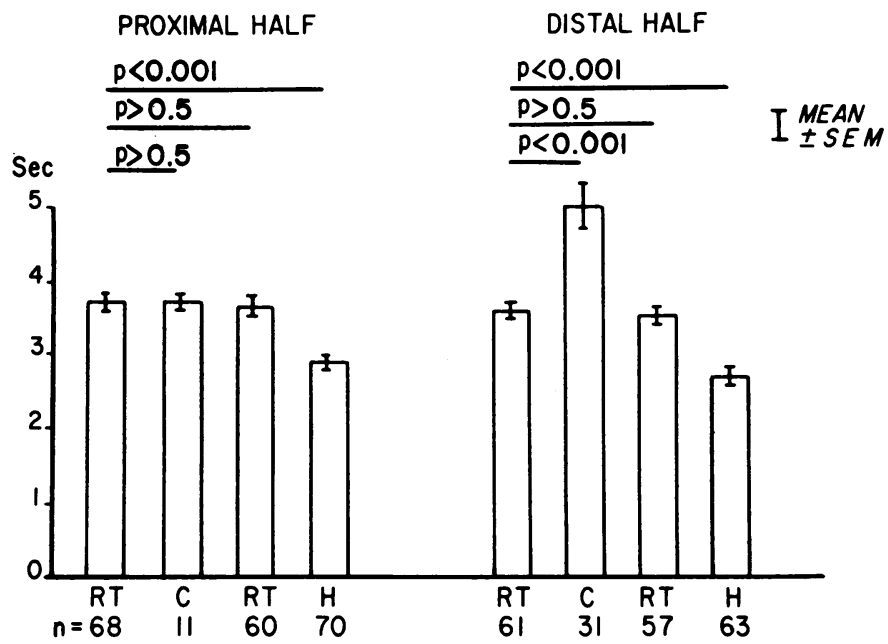

FIgURE 7 Duration of monophasic waves.

slightly around $1^{\circ} \mathrm{C}$, as does iced water. Hunt (2) reported that the preferred temperature of hot drinks among young adults in Great Britain was $60^{\circ} \mathrm{C}$. This temperature preference may not be exactly duplicated by citizens of the United States but it is probably close.

It is clearly of physiologic interest, therefore, that water (and presumably other liquids) ingested at these temperatures profoundly alter human esophageal motor function.

The effects, as might be expected, are opposites. The response to iced water is a slowing or abolition of esophageal motor activity whereas acceleration of motor activity occurs with $\mathrm{H}$ water.

The LES exhibited a slowing of function with $\mathrm{C}$ water, but retained its ability to relax and contract even when motor function had been entirely abolished in the body of the esophagus proximally. In fact, the ingestion of $\mathrm{C}$ water resulted in increased amplitude of contraction of the LES.

None of these changes, however, were demonstrable in the UES and most proximal $2 \mathrm{~cm}$ portion of the body of the esophagus which is presumably within the striated muscle portion of the esophagus. Comparable temperature changes were registered throughout the esophagus; and therefore, allow us to implicate neither the degree of temperature change nor differences in technique of studying different esophageal segments as cause for the observed sparing of the UES and the most proximal esophagus from the effects of $\mathrm{C}$ and $\mathrm{H}$ liquid bolouses.

The question arises whether the observed differences are myogenic or neurogenic. We cannot answer this question conclusively; but since the effects are most apparent only in the smooth muscle portion of the esophagus, since the changes occur in a progressive fashion with increasing exposure to hot or cold, and since they are similar to alterations effected by temperature changes in vascular smooth muscle (3) and myocardium $(4,5)$, it seems most likely that the changes in esophageal motor function are secondary to changes in smooth muscle contractibility in response to temperature variations.

The possibility of a neurogenic influence cannot be excluded, however. In favor of this possibility is the report by Ellis, Kauntze, and Trounce (6) that cooling of human esophageal muscle strips to $14^{\circ} \mathrm{C}$ in vitro inhibits nerve-mediated responses to short duration pulse waves, whereas long duration pulse waves continue to evoke responses from the less sensitive muscle fibers. Additionally, abolition of response by cold was observed in the present study only in the distal portion of the body of the esophagus but not in the similarly smoothmuscled lower esophageal sphincter. Finally, changes in motor function were often identifiable with the first swallow or two at a new temperature even though several swallows were usually required for the changes to become fully developed (Fig. 6).

Respess, Ingelfinger, Kramer, and Hendrix (7) described changes in human esophageal motor function after ingestion of iced water and iced barium. They observed dilatation of the cooled esophagus, and the final positive wave of the swallowing complex was usually abolished. Fluoroscopically, there was dilatation of the gastroesophageal segment and barium flowed readily into the stomach without benefit of peristalsis. Neither topical cocainization of the esophagus nor administration of an anticholinergic medication completely reproduced the effects of cold. These latter observations further suggest that the effects of variable temperature is ex-

Bolus Temperature and Esophageal Motility 249 
erted upon the muscles. It would be interesting to observe persistence of the same responses to $\mathrm{C}$ and $\mathrm{H}$ boluses after topical cocainization.

Although the report by Respess, Ingelfinger, Kramer, and Hendrix (7) was primarily descriptive with little specific data, the changes which occurred in the body of the esophagus with ingestion of cold water were essentially those we observed. There seems to be some discrepancy, however, in the behavior of the inferior esophageal sphincter in their study as compared to ours. They observed no visible resistance to the flow of iced barium through the gastroesophageal segment. Our thermistor recordings indicated that there frequently was pooling of iced water in the distal esophagus and delayed entry into the stomach. It is difficult to explain this pooling from the pressure characteristics of the sphincter; the sphincteric yield pressure decreased appropriately after swallows even when the peristaltic wave above was abolished, and the degree of relaxation was not different than observed with $\mathrm{RT}$ or $\mathrm{H}$ water swallows. There was, however, a significant delay in achieving complete sphincteric relaxation with ingestion of cold water; but once achieved, the relaxation persisted longer than when water of warmer temperature was drunk. The delay in achieving maximal relaxation seems the most likely cause for the holdup of cold water in the distal esophagus. This answer is not completely satisfactory, however, since the observed delays in entry of cold water in the stomach were frequently considerably longer than the maximum observed delays in sphincteric relaxation.

\section{ACKNOWLEDGMENTS}

This work was supported in part by grants 1-R01-AM-11866 and 5-M01-FR-00058 from the National Institutes of Health and from the Patrick and Anna M. Cudahy Fund.

\section{REFERENCES}

1. Snedecor, G. W. 1956. Statistical Methods. Iowa State University Press, Ames. 5th edition.

2. Hunt, J. N. 1947. The temperature of choice for hot drinks: a comparison of men and women. Guy's Hosp. Rep. 96: 60 .

3. Wiederhielm, C. A. 1967. Effects of temperature and transmural pressure on contractile activity of vascular smooth muscle. Bibl. Anat. 9: 321.

4. Kruta, V. 1937. Variations de la duree de la contraction du muscle cardiaque en fonction du rythme et de la témperature. C. R. Soc. Biol. 125: 498.

5. Sumbera, J., V. Kruta, and P. Braveny. 1966. Influence of a rapid change of temperature on the mechanical response of mammalian myocardium. Arch. Int. Physiol. Biochem. 74: 627.

6. Ellis, F. G., R. Kauntze, and J. R. Trounce. 1960. The innervation of the cardia and lower oesophagus in man. Brit. J. Surg. 47: 466.

7. Respess, J. C., F. J. Ingelfinger, P. Kramer, and T. R. Hendrix. 1956. Effect of cold on esophageal motor function. Amer. J. Med. 20: 955. (Abstr.) 